\title{
Leitores-navegantes de textos e hipertextos da literatura
}

\author{
Paula Tatianne Carrèra Szundy ${ }^{a}$ \\ Luciana Marino Nascimento ${ }^{b}$
}

\begin{abstract}
Resumo
O presente artigo propõe-se a refletir sobre práticas de leitura de textos literários ressignificadas na web de forma a criar inteligibilidade sobre os (multi) letramentos da esfera literária com os quais leitores contemporâneos se engajam no mundo virtual. Para compreender essas práticas, recorremos a constructos sobre leitura e leitores literários (CERTEAU, 1994; CHARTIER, 1998; BARTHES, 1987), sobre a leitura na Internet (BRAGA, 2005; COSTA, 2009), sobre (multi)letramentos (COPE, KALANTZIS et al, 2000; ROJO, 2012, 2013) e às concepções de dialogismo, gêneros do discurso e hibridismo desenhadas pelo Círculo de Bakhtin (VOLOSHINOV, 1929 [1999]; BAKHTIN, 1953 [2011]). De forma a (re)pensar sobre como leitores navegantes de textos e hipertextos (re/des)constroem sentidos de textos literários na Internet, tomamos práticas de (multi) letramentos com ciberpoemas no site ciberpoesia.com. br como objeto de análise.
\end{abstract}

Palavras-chave: leitores-navegantes, hipertextos, ciberpoemas, multiletramentos

Recebido em 27 de novembro de 2015 Aceito em 13 de janeiro de 2016

a Professora da UFRJ e presidente da Associação de Linguística Aplicada do Brasil (2016-2017), ptszundy@ uol.com.br

${ }^{\text {b }}$ Professora da UFRJ e bolsista de Produtividade em Pesquisa (PQ2) do CNPq, zensansara@bol.com.br 
Os leitores são viajantes; circulam em terras alheias; são nômades que caçam furtivamente em campos que não escreveram.

Michel De Certeau

\section{Introdução}

Ao começarmos pela epígrafe de De Certeau (1994), podemos observar que os sentidos da leitura vão além da simples decodificação de sinais de gráficos. Nenhuma epígrafe é, portanto, gratuita, mas antes constitui uma prática de leitura intertextual. O historiador francês destaca a condição do leitor como um sujeito criativo, caçador e viajante, pois a leitura não constitui algo fixo, mas se trata de um sistema dinâmico de invenção e de multiplicidade, pois o leitor "insinua as astúcias do prazer e de uma reapropriação no texto do outro: aí vai caçar, ali é transportado, ali se faz plural como o ruído do corpo. A leitura introduz, portanto, uma arte que não é passividade." (CERTEAU, 1994, p. 49).

Como leitoras da epígrafe de De Certeau situadas em uma visão sócio-histórica da linguagem no âmbito da Linguística Aplicada, vemos, a partir das nossas próprias histórias como leitoras-pesquisadoras, possibilidades de intertextualidades com a concepção de dialogismo postulada pela filosofia da linguagem do Círculo de Bakhtin. Isso porque, como nos lembra Brait (1997), o dialogismo nos postulados bakhtinianos pode ser compreendido como o componente que institui a natureza interdiscursiva da linguagem na medida em que se refere "ao permanente diálogo, nem sempre simétrico e harmonioso, existente entre os diferentes discursos que configuram uma comunidade, uma cultura, uma sociedade" (BRAIT, 1997, p. 98), assim como elemento representativo das relações discursivas entre o eu e o outro nos processos discursivos instaurados historicamente pelos sujeitos, processos discursivos pelos quais os sujeitos também são instaurados.

Por se constituírem, a um só tempo, sujeitos e agentes de processos discursivos sempre em vias de (des/re)construção, as atitudes dos leitores perante os textos de outrem são, conforme destaca Voloshinov (1929 [1999]), sempre responsiva-ativas e prenhes à avaliações ideológicas sócio, histórica e culturalmente (re)situadas. Logo, em suas viagens por textos literários na 
Internet, leitores-internautas reavaliam e ressignificam esses textos através de caminhos que são próprios dessa esfera virtual, possibilitados, especialmente, por um cronotopo organizado a partir de links e hiperlinks e por uma maior possibilidade de (inter)diálogos entre diferentes semioses (multimodalidade). As reelaborações a que textos literários estão sujeitos na Internet acabam, portanto, por engajarem leitores em viagens distintas daquelas que observamos na leitura de obras literárias impressas.

Roland Barthes em seu livro O prazer do texto (1987), nos mostra que o texto literário se torna ficção de um sujeito que o reelabora a partir de sua experiência e de seu repertório cultural. No entanto, a leitura como prática solitária e linear vem sendo reatualizada pelas novas mídias digitais, tendo em vista que a própria leitura se constitui num dado momento e requer, por assim dizer, suportes diferentes em diferentes épocas:

Os gestos mudam segundo os tempos e lugares, os objetos lidos e as razões de ler. Novas atitudes são inventadas, outras se extinguem. Do rolo antigo ao códex medieval, do livro impresso ao texto eletrônico, várias rupturas maiores dividem a longa história das maneiras de ler. Elas colocam em jogo a relação entre o corpo e o livro, os possíveis usos da escrita e as categorias intelectuais que asseguram sua compreensão. (CHARTIER, 1998, p. 77)

A leitura na tela do computador modificou o modo do leitor lidar com o texto, pois se exige outra postura do corpo, certamente diferente daquela utilizada na leitura do papiro ou do livro impresso. Uma mudança importante na relação entre o corpo e o livro no espaço virtual está nas possibilidades ampliadas de (inter)ações com o texto nesse espaço. A imagem do leitor compenetrado e solitário parece não traduzir mais as experiências de (re)leitura propiciadas pela Internet, onde as possibilidades de interações síncronas e assíncronas com outros leitores e, especialmente, as situações em que comunidades de leitores reescrevem e reinterpretam textos literários, tornandose, dessa forma, também autores, instauram leitores-autores em processos discursivos outros.

Partindo do pressuposto de que a compreensão de tais processos é fundamental no âmbito dos estudos situados da linguagem tanto pela relevância que exercem na (re/des) construção de sentidos legitimados na esfera literária quanto 
por suas possíveis implicações pedagógicas, o presente artigo propõe-se a refletir sobre práticas de leitura de textos literários ressignificadas na web de forma a criar inteligibilidade sobre os (multi)letramentos da esfera literária com os quais leitores contemporâneos se engajam no mundo virtual.

Para tal, iniciamos o artigo apresentando as concepções que fundamentam nossa reflexão sobre 1. Leituras e leitoresnavegantes da Internet e 2. Linguagens e (multi)letramentos. Em seguida, com o intuito de problematizar como leitoresnavegantes de textos e hipertextos (des/re)constroem sentidos de textos literários na Internet, tomamos algumas práticas de (multi)letramentos com textos literários na web como objeto de análise: 3. Práticas de (multi)letramentos com textos literários na web. Por fim, nas Considerações Finais, esboçamos algumas implicações linguístico- pedagógicas das práticas de leitura literária na Internet.

\section{Leituras e leitores navegantes da Internet}

Com o surgimento dos textos digitalizados, diferentemente do suporte do livro, o leitor não se debruça sobre a obra de leitura, mas se coloca diante de uma tela com olhar para frente, perpendicularmente à sua visão, ou seja, não se apropriando mais da corporalidade do texto, mas constituindo uma leitura em que não se exige mais do corporal, como no códice, no papiro ou no livro impresso. É notória a diferença de relação que se estabelece na leitura no suporte material do livro e do computador entre o leitor, até mesmo porque a internet criou também uma gama de gêneros textuais a partir daqueles já conhecidos, como bem afirma Costa (2009):

A internet ofereceria, pois, uma variedade imensa de novos tipos de textos (gêneros [hiper]textuais) que podem ser lidos/ recebidos ou escritos/produzidos com os vários recursos técnicos que o computador coloca à disposição. Páginas pessoais, sítios, portais (homepages), entendidos por uns como gêneros, por outros como ambientes de localização de informações, conversas em salas de bate papo (chats), salas de discussão (fóruns), correios eletrônicos (e-mails) e outros são novos ambientes e/ou gêneros (hiper)textuais à disposição dos usuários. (COSTA, 2009, p. 21-22) 
Dessa forma, observa-se que para cada suporte de escrita mobilizam-se estratégias distintas para a leitura. Nesse sentido, tanto o suporte material dos textos quanto a forma como o texto é lido são fundamentais para a estruturação de sentidos, significados e interpretação da leitura. No entanto, mesmo diferentes, as práticas de leitura e escrita apresentam similaridades entre o livro na sua materialidade e os gêneros textuais tradicionais, conforme postula Costa (2009):

Haveria, então, nesse cenário várias semelhanças e diferenças entre os gêneros textuais existentes e os emergentes. Muitos pesquisadores de textos produzidos na internet apontam, por exemplo, no nascimento de alguns gêneros que, embora tenham semelhanças com gêneros já existentes, não são os mesmos. Assim, embora usados na comunicação interindividual, o correio eletrônico (e-mail) é diferente da carta (correspondência epistolar), o bate papo virtual (chat) é diferente de uma conversa face a face ou telefônica. (COSTA, 2009, p. 22).

Em consonância com a transmutação dos gêneros digitais sinalizada por Costa (2009), seria razoável, a partir da perspectiva bakhtiniana que destaca a heterogeneidade dos gêneros discursivos e como a transformação constante das atividades humanas transformam gêneros existentes e (re)criam novos (BAKHTIN, 1953 [2011]), propor que, embora mantenham traços que os relacionem historicamente a gêneros anteriores (o e-mail com a carta e o blog com o diário, por exemplo), os inúmeros gêneros digitais com que nos deparamos na Internet possuem características próprias em termos de conteúdo, estrutura e estilo composicional.

Após essas considerações iniciais acerca da leitura na Internet, perguntamos, enfim, quais mudanças a leitura de textos literários vem sofrendo na contemporaneidade, num tempo de rapidez e numa sociedade digital?

Ao abordarmos a leitura do texto literário na tela do computador, nos remetemos às reflexões de Ítalo Calvino, em seu livro Seis propostas para o próximo milênio, no qual Calvino postula que a linguagem literária deve ter rapidez e visibilidade. A rapidez e a visibilidade, hoje, se tornaram palavras de ordem na nossa contemporaneidade, época em que incorporamos o expansionismo da visualidade. Calvino assim nos ensina: 
Se incluí a Visibilidade em minha lista de valores a preservar foi para advertir que estamos correndo o perigo de perder uma faculdade humana fundamental: a capacidade de pôr em foco visões de olhos fechados, de fazer brotar cores e formas de um alinhamento de caracteres alfabéticos negros sobre uma página branca, de pensar por imagens. Penso numa possível pedagogia da imaginação que nos habitue a controlar a própria visão interior sem sufocá-la e sem, por outro lado, deixá-la cair num confuso e passageiro fantasiar, mas permitindo que as imagens se cristalizem numa forma bem definida, memorável, auto-suficiente. (CALVINO, 1990, p. 107-108).

A disponibilização do texto literário na tela do computador corresponde ao que Walter Benjamin já havia apontado em seu ensaio A Obra de arte na época de sua reprodutibilidade técnica, ou seja, a dessacralização da arte e do artista enquanto um ser especial, dotado de qualidades divinas. Benjamin, ao mostrar que a arte perdeu a sua aura de objeto único, nos aponta que a arte se tornou um produto cultural, tendo em vista as técnicas de reprodução, ou seja, "a arte contemporânea será tanto mais eficaz quanto mais se orientar em função da reprodutibilidade e, portanto, quanto menos colocar em seu centro a obra original" (BENJAMIN, 1996, p.130).

Se trouxermos as reflexões de Benjamin para a cena literário-artística atual, podemos verificar a obra na sua reprodutibilidade técnica. Citemos como exemplo, o site Ciberpoesias, de Sergio Caparelli e Ana Claudia Gruszinski. Primeiramente, os escritores lançaram o livro Poesia Visual e, posteriormente, criaram o site Ciberpoesia para divulgar o livro. Neste site, são disponibilizados poemas visuais e poemas visuais interativos com espaço para o leitor manifestar sua opinião, ou seja, a obra literária pode ser elaborada e reelaborada por muitas mãos, a partir de uma escrita inicial. Um dos exemplos é o poema Chá, de Sergio Caparelli e Ana Claudia Gruszinski, com animações e ilustrações de Francisco Baldini.

Para ler e elaborar este poema, o leitor arrasta vários ingredientes para preparar um chá e ao final, surge um poema tomando-se de empréstimo, o gênero discursivo da receita culinária. 
Figura 1 - Poema Chá.

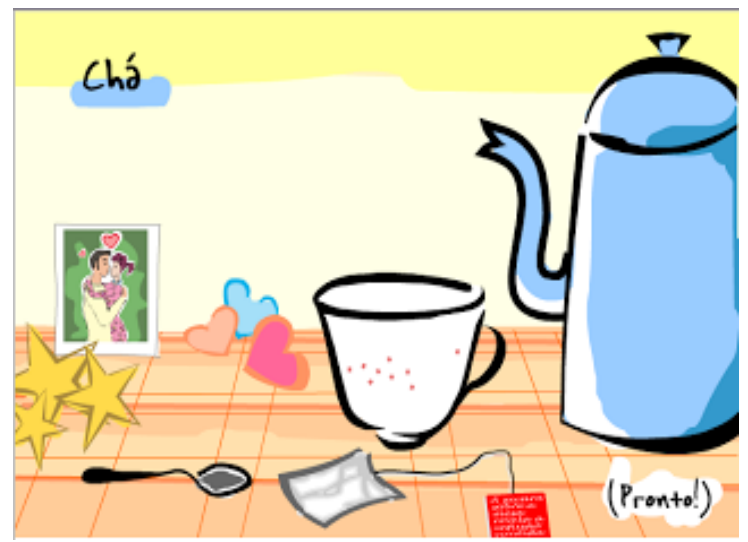

Fonte: www.ciberpoesia.com.br. Acesso em 10/11/2014

1 As críticas de Rojo (2013b) estão relacionadas aos processos de didatização de gêneros textuais baseados na proposta de modelização didática proposta pelo Grupo de Genebra (SCHNEUWLY, DOLZ et al, 2004). A proposta do Grupo, voltada para o ensino da produção escrita em francês como língua materna na Suíça francófona, está baseada na construção de modelos didáticos a partir de sequências didáticas, compreendidas como "um conjunto de atividades escolares organizadas, de maneira sistemática, em torno de um gênero textual oral ou escrito" (DOLZ, NOVERRAZ E SCHNEUWLY, 2004, p. 97). O trabalho do Grupo tem influenciado consideravelmente práticas de ensino-aprendizagem de línguas (maternas e adicionais) no Brasil, influência que pode ser claramente percebida, por exemplo, nos $\mathrm{Pa}$ râmetros Curriculares de Língua Portuguesa (BRASIL, 1998).
Embora Rojo (2008) compreenda que ler é se apropriar de signos e sentidos através do estudo dos gêneros e que escrever é se apropriar dos gêneros, em um texto posterior, a autora (ROJO, 2013b) critica a forma como os gêneros vêm sendo didatizados na escola partindo da premissa que tais processos de didatização não dão conta da plasticidade dos gêneros na esfera digital ${ }^{1}$. Uma das razões pelas quais o trabalho de didatização de gêneros para o ensino da compreensão e produção escrita na escola não daria conta de práticas como a encontrada no poema Chá está no fato de essas práticas serem orientadas pela análise e/ou (re)produção das características estáveis do gênero partindo de modelos extraídos de um corpus representativo e, portanto, canônico do(s) gênero(s) didatizado(s). Como os gêneros digitais, a exemplo do poema acima, são caracterizados pelo hibridismo e mestiçagem de gêneros, conteúdos e estilos, Rojo (2013a e b) defende uma abordagem mais flexível e plástica para o estudo dos gêneros que, segundo a autora, ainda encontra ecos na filosofia da linguagem delineada pelo Círculo de Bakhtin.

Se tomarmos o caso do texto literário na tela computador, percebemos que através de links, hiperlinks, lemos, por exemplo, a obra de Machado de Assis digitalizada, ilustrada por fotos, no site http://www.machadodeassis.org.br/ ou Fernando Pessoa "revisitado", a partir de uma leitura dinâmica, em que se pode visualizar fotos, poemas e as frases mais famosas do 
2 Hipertexto e hipertextualidade são termos usados sem distinção por autores tais como MARCUSCHI, (2005); ARAUJO (2006); COSCARELLI (2006). poeta português em www.cfh.ufsc.br/ magno, ou mesmo é possível ouvir o ator Paulo José declamando o famoso poema de Pessoa Mar Portuguez ao acessar o site YouTube (www. youtube.com/watch? $v=6 \mathrm{iHHvNI6OKQ.)}$.

Observa-se que a literatura e a tela do computador já estão bem sintonizados. Basta percorrermos a rede mundial de computadores para constatarmos que não só a obra de autores canônicos e consagrados da literatura brasileira e mundial se fazem presentes, como também é possível notarmos uma grande variedade de blogs, microblogs, sites de autores estreantes de todas as idades, ou seja, quase todos se permitem tornar escritores de literatura. Eis a "literatela" em cena (OLIVEIRA, 2010, p. 4).

Essa disponibilidade de textos literários ou não literários na rede mundial de computadores enseja, sem dúvida, novas práticas de leitura, leitura essa que perpassa uma hipertextualidade ${ }^{2}$, cujo suporte é a tela do computador. Pierre Levy assim caracteriza o hipertexto: “O hipertexto seria constituído de nós (os elementos de informação, parágrafos, páginas, imagens, sequências musicais etc.) e de ligação entre esses nós (referências, notas, indicadores, botões que efetuam a passagem de um nó a outro)" (LÉVY, 1996, p. 44).

Ao falarmos de hipertexto, surge em nosso pensamento a ideia de algo que despontou com a abertura e a popularização da rede mundial de computadores, mas se lembrarmos aqui da obra Glas, de Jacques Derrida, podemos observar nela, o antecedente do hipertexto contemporâneo. A obra do filósofo foi publicada em 1974 e cada página se encontra dividida em duas colunas, sendo que na coluna da direita o autor dispõe reflexões filosóficas de Hegel e na coluna da esquerda encontramos comentários críticos acerca de obras e termos literários, criando um espaço textual muito particular e rompendo, assim, com a linearidade tradicional do livro, assemelhando-se, portanto, ao que hoje observamos no hipertexto dos sites. Observe-se uma das páginas da Obra Glas, de Derrida. Na página destacada por nós, na primeira coluna, Derrida discorre sobre a Fenomenologia do espírito, de Hegel, acrescentando notas explicativas sobre termos empregados pelo filósofo; sendo que a segunda coluna é composta por verbetes cujas fontes estão na obra de Genet, cujas 
palavras apresentam similaridade fônica e morfológica, tendo -Cata como radical comum: "Catachrèse, Catafolque, Cataglotisme", ou seja, embora tais campos semânticos não mantenham relação de sinonímia, estes se conectam intertextualmente, pela apropriação que Derrida faz da obra de Genette Figuras de Linguagem, como também pelo sentido figurado da ideia de decadência e desconstrução, pois o radical - cata indica movimento para baixo. A catacrese constitui figura de linguagem, catafalque constitui palavra derivada do Italiano Catafalco e significa plataforma funeral de apoio ao caixão e o cataglotismo constitui vício de linguagem e diz respeito ao uso de palavras rebuscadas.

Ao fazer uso de uma escrita baseada nos " restos e fragmentos", Derrida fecha a segunda coluna com o enunciado “O resto é indizível, quase: não por aproximação empírica, mas ao rigor indeciso," o que para Gaston (2012) constitui uma re-citação, restos de um palimpsesto, pensamento de restos/resíduos que ainda faltam ser pensados."(GASTON, 2012, p. 157.).

Figura 2 - Página da obra Glas, Derrida.
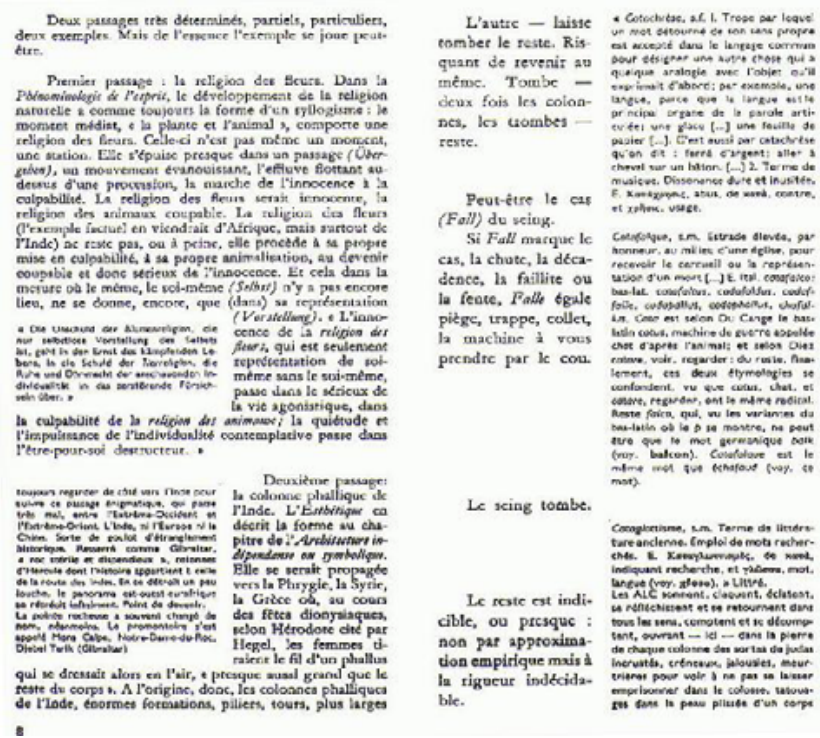

Fonte: http://www.unicamp.br/ hans/mh/intersec.html. Acesso em 10/11/2014. 
Embora, o hipertexto seja visto como novidade, podemos indagar se de fato e em que medida o hipertexto na tela do computador é composto de elementos novos em relação ao texto impresso? Nesse aspecto, Landow assinala que "no hipertexto corre um feixe de significantes presentes, através do qual os leitores podem adentrar inúmeras estradas sem que nenhuma delas seja considerada a principal via". (LANDOW, 1995, p. 74.).

Sobre o texto de Derrida, Landow assinala que se trata de um texto aberto, que permite o jogo, operando múltiplas configurações, a partir de fragmentos. Ao lançar mão dos conceitos baktinianos de polifonia e textualidade, o autor norteamericano mostra que na arquitetura do hipertexto a voz única de um texto perde a sua soberania pela referência a outros textos, como também assinala que o todo da textualidade não se apresenta de forma acabada, pois a linguagem é construída continuamente no contexto social, em confronto com o discurso do outro. Assim, o hipertexto com seus nós permite ao leitor atravessar diversos textos, como numa grande rede, pois na rede mundial de computadores cada endereço estabelece pontes e nós com outros sites, sendo que cada palavra-chave destacada aponta para o mesmo assunto ou para assunto correlato. Segundo Ingedore Koch, esses nós "permitem ao leitor realizar livremente desvios, fugas, saltos instantâneos para outros locais virtuais da rede, de forma prática, cômoda e econômica." (KOCH, 2005, p. 63).

Essa incessante busca de informação, sendo que cada informação leva o navegante a outra informação e assim sucessivamente, nos aponta para a metáfora proposta por Jorge Luiz Borges, em seu conto A Biblioteca de Babel, ou seja, uma biblioteca que abrigaria todos os textos escritos e os que ainda seriam escritos:

"Quando se proclamou que a Biblioteca abarcava todos os livros, a primeira impressão foi de extravagante felicidade. Todos os homens sentiram-se senhores de um tesouro intacto e secreto." (BORGES, 2007, p. 69)

Se, por um lado, a exploração situada de algumas das práticas de (multi)letramentos a partir das quais leitoresinternautas ininterruptamente ressignificam e recirculam textos literários na Internet já justificaria nosso interesse como linguistas aplicadas em explorar parte dessa Biblioteca, 
consideramos importante, por outro, também voltar nosso olhar para o potencial pedagógico de algumas das práticas que nela se (des/re)constroem. Isso porque compartilhamos com Braga (2005) a visão de que uma abordagem crítica e informada acerca do uso da Internet como ferramenta pedagógica pode propiciar um ambiente mais democrático para a circulação textual que favorece (re)leituras mais amplas devido à possibilidade de contrastar e comparar diferentes fontes de informação propiciada por uma Biblioteca organizada em links e hiperlinks.

Além disso, acreditamos que a hibridização das múltiplas semioses tais como sons, fotos, vídeos, texto, que contribuem para a (re/des)construção de significados nos inúmeros gêneros encontrados na web, gera um ambiente privilegiado para o desenvolvimento da leitura e escrita multimodal, elementos cruciais para cultivar uma cidadania capaz de compreender e construir significados no mundo em que vivemos (Ramanathan e Morgan, 2005).

Dado o fato de que a leitura/escrita multimodal é fundamental para compreensão das práticas de (multi) letramentos que leitores navegantes de textos literários (re) constroem na Internet, passamos a seguir a descrever as concepções de linguagens e (multi)letramentos que orientam a nossa reflexão sobre essas práticas.

\section{Linguagens e (multi)letramentos}

A partir do pressuposto de que práticas pedagógicas responsivas à contemporaneidade devem, necessariamente, promover tanto a compreensão quanto o posicionamento crítico em relação aos (multi)letramentos que (des/re) constroem significados sobre a vida social, Szundy (2014) e Oliveira e Szundy (2014) destacam que princípios defendidos pela pedagogia dos multiletramentos proposta pelo Grupo de Nova Londres (2000) podem, em diálogo com concepções de linguagem delineadas pelo Círculo de Bakhtin, prover pesquisadores, professores e formadores com um instrumental teórico-analítico suficientemente plástico e flexível "capaz de transformar enunciados cristalizados para aliviar, como quer a Linguística Aplicada, as inúmeras privações sofridas no cenário educacional brasileiro" (SZUNDY, 2014, p. 14). 
Dentre as várias concepções de linguagem desenhadas pelo Círculo de Bakhtin, àquela de hibridização como "mistura de duas linguagens sociais no interior de um único enunciado, [...] o reencontro na arena deste enunciado de duas consciências linguísticas, separadas por uma época, por uma diferença social (ou por ambas) (BAKHTIN, 1975 [1998], p. 156)" parece imperativa para compreender as práticas de (multi)letramentos da contemporaneidade, especialmente àquelas que leitores $\mathrm{e}$ escritores navegantes (re)encontram e transformam na Internet.

Ao propor uma pedagogia dos letramentos que dê conta da multiplicidade cultural, da heterogeneidade de letramentos e da mistura de semioses, a concepção de multiletramentos proposta pelo Grupo de Nova Londres (2000) parece conversar com a noção de hibridização do círculo de Bakhtin. Conforme sinaliza Rojo:

[...] diferentemente do conceito de letramentos (múltiplos), que não faz senão apontar para a multiplicidade e variedade das práticas letradas, valorizadas ou não nas sociedades em geral, o conceito de multiletramentos aponta para dois tipos específicos e importantes de multiplicidade presentes em nossa sociedade, principalmente urbanas, na contemporaneidade: a multiplicidade cultural das populações e a multiplicidade semiótica de constituição dos textos por meio dos quais ela se informa e comunica. (ROJO, 2012, p. 13)

A importância dos processos de hibridização é enfatizada por Luke (2000) em relação aos "multiletramentos de textos digitais eletrônicos" (p. 73). Luke (2000) destaca que, por serem construídos a partir da hibridização e intertextualidade, multiletramentos nesses textos requerem conhecimentos tanto de gêneros tradicionais quanto de gêneros misturados, ou seja, híbridos. Pelo fato de a navegação hipertextual requerer uma leitura multimodal, a autora destaca ainda que o letramento linear baseado no texto impresso e aplicado na compreensão e produção de gêneros tradicionais não mais responde às competências requeridas para uma leitura e escrita multimodal.

Como a Comunicação Mediada por Computador (CMC) representa um híbrido da linguagem do livro e da tecnologia computacional, as práticas de leitura e escrita também estão em fluxo na $\mathrm{CMC}$, requerendo letramentos modais e multimidiáticos (Luke, 2000). No que diz respeito a tais letramentos, Luke sinaliza que: 
Tradução nossa para "[...] we don't read electronic text onscreen in the exclusively bookish direction from left to right but we scroll text vertically with increasingly speed and visual acuity in order to identify the gist of a message and locate keywords on which to click. [...] These blended vocabularies and reading-writing practices require new multimodal and multimedia literacies that combine the horizontal linearity of print with the vertical scrolling and laterally connected (button 'hotlinks') features of electronic texts".
[...] nós não lemos texto na tela exclusivamente na direção do livro da esquerda para a direita mas rolamos o texto verticalmente em velocidade e acuidade crescentes para identificar a essência da mensagem e localizar palavras-chaves em que clicar. [...] Esse vocabulário misturado e práticas de leitura-escrita requerem novos letramentos multimodais e multimidiáticos que combinam a horizontalidade linear do impresso com a rolagem vertical e a lateralidade conectada (botões 'hotlinks') características de textos eletrônicos. (LUKE, 2000, p. 84) ${ }^{3}$

Apesar de enfatizar a legitimidade das práticas de escrita e leitura digitais e entender que, pedagogicamente, a aprendizagem na Internet pode encorajar alunos e professores a se arriscarem mais e a se engajarem na resolução colaborativa de problemas, Luke (2000) está longe de adotar uma postura tecnólatra em relação à aprendizagem mediada pelas novas tecnologias. Contrariamente a essa postura, a autora denuncia o imperialismo cultural e machismo presentes na CMC e a desigualdade de acesso determinada por fatores geográficos, raciais e de gênero.

Para Luke (2000), tais problemas corroboram a necessidade de aplicar três princípios básicos dos letramentos críticos à $\mathrm{CMC}$, quais sejam: metaconhecimento de como conhecimentos, ideias e informações estão estruturados em diferentes gêneros e como tal estrutura afeta o processo de (re/des)construção de significados; conhecimento técnico e analítico que leve à compreensão de como as pragmáticas de uso dos letramentos são traduzidas e interpretadas em diferentes contextos; e capacidade de compreender como as práticas de letramento respondem a interesses e relações de poder em e através de diferentes instituições sociais.

No que diz respeito ao poder que determinados grupos sociais e as instituições que os representam exercem sobre a (des)legitimação de determinados modos de realização semiótica de significados no mundo social, Kress (2000) chama atenção para o fato de que a escrita tem sido sobrevalorizada em relação à fala e a todos os outros modos com os quais o ser humano corporalmente se engaja em processos de (des) construção de sentidos, como, por exemplo, o visual e o táctil. Como consequência dessa sobrevalorização, o autor destaca o desenvolvimento da ideologia, bastante arraigada em 
diferentes culturas ocidentais, da existência de uma gramática universal da língua. Por alimentar a crença de que as línguas são meios representacionais e comunicacionais capazes de expressar todo e qualquer significado, Kress entende que tal ideologia dificulta a percepção da natureza multimodal da linguagem. Na sociedade da informação e do conhecimento em que vivemos na contemporaneidade, a implicação epistemológica dessa não percepção é que "nós, no Ocidente, nos encontramos singularmente mal equipados perante a nova paisagem da comunicação, seja no sentido geral, ou na educação institucional ou não-institucional ${ }^{4 \prime}$ (KRESS, 2000, p. 183).

Como alternativa, Kress (2000) propõe o desenvolvimento de uma nova agenda no domínio da comunicação capaz de teorizar e descrever os diversos modos de realização de significados em determinada sociedade, como esses modos se inter-relacionam, quais são suas limitações e potenciais no desenho de novos futuros sociais, agenda esta que o autor entende como prioritária em uma pedagogia dos multiletramentos. A assunção básica defendida por Kress é que o trabalho com os e as análises dos discursos devem necessariamente incorporar textos que apareçam em outras formas que não linguísticas e tratar todo objeto textual como multimodal. O tratamento dos modos semióticos e das formas pelas quais suas materialidades são realizadas devem, por sua vez, ser relacionados com as formas pelas quais o corpo humano (o ser humano corporificado) mobiliza diferentes modos semióticos em processos de (re/des)construção de significados e também com as relações desses modos com seus meios de transmissão e propagação.

Mobilizar os princípios sugeridos por Luke (2000) e Kress (2000) na reflexão sobre os multiletramentos literários em que leitores-navegantes se engajam na Internet pode, além de lançar luz sobre essas práticas de usos das linguagens literárias na web, contribuir para instaurar, em possíveis

4 Tradução nossa para
"[...] we, in the 'West', find ourselves ill-equipped in the new landscape of communication, whether that is generally speaking, or institutional or noninstitutional education". (KRESS, 2000, p. 183). projetos pedagógicos envolvendo tais textos, uma estética imbricada com o existir-evento e com o ato ético (BAKHTIN, 1920-24 [2010]), pois, conforme sublinha Szundy:

A apreciação estética fundada na ética pressupõe o reconhecimento de múltiplas estéticas, a valorização do conhecimento e critérios estéticos de outrem, a abertura de espaços 
na escola para apreciação responsiva de obras ainda não reconhecidas como cânones. Pressupõe também a relação da arte, da literatura, da música com a geografia, história, língua materna e estrangeira, educação física, biologia, matemática e todas as demais áreas do conhecimento, já que uma apreciação estética inscrita no existir-evento não deve ser limitada por barreiras disciplinares. Pressupõe, por fim, a hibridização de produções artísticas marginalizadas e canônicas em um processo de construção de sentido sempre localizado histórica e socialmente. (2014, p. 23)

Na seção que se segue, buscamos caminhos analíticos para o exercício de apreciação estética de práticas de multiletramentos de textos literários pelas quais leitores e escritores navegam na Internet para, em seguida, refletir sobre as implicações linguístico-pedagógicas de tais práticas.

\section{Práticas de (multi)letramentos com textos literários na web}

De acordo com Kleiman (2000), o suporte por onde circula um texto constitui um elemento paratextual, cuja leitura se torna um importante instrumento para conhecermos a intencionalidade do enunciador do texto, não se resumindo, portanto, ao espaço ou local onde se encontra um determinado texto. Dessa forma, pensando o ciberpoema como bem de consumo engendrado pela nossa contemporaneidade, compreendemos esse gênero como poesia que permite interação do seu leitor virtual na medida em que "o poema pede um tipo de leitura com disposição para o rompimento" (VERSIANI, 2003, p. 51). Considerando-se que poema e ciberpoesia constituem gêneros diferentes, embora apresentem pontos em comum, como o efeito estético da palavra e a literariedade:

A ciberpoesia, portanto, nada mais é do que uma nova expressão poética do nosso tempo. Uma única voz ativa é relativizada. Tal como a figura do receptor. Assim, sendo também uma filha da internet e do ciberespaço, ambos meio e espaço híbridos, a ciberpoesia possui uma construção híbrida, tanto na linguagem (multimidiática) quanto no modo de acesso (amplamente disponível). Áudio, texto escrito e a estrutura de jogos virtuais fundem-se, e confundem-se, a fim de atingir o plano da poesia neste novo momento. (DANTAS, el al. 2010, p. 1) 
Ana Cláudia Gruszynski e Sérgio Capparelli, autores de ciberpoemas e do site ciberpoesia.com.br assinalam que na nossa contemporaneidade as fronteiras entre os gêneros são bastante fluidas:

Os tipos e as letras passam a ser aceitos em sua materialidade: o som, com a busca do dinamismo dos objetos; o peso, com o reconhecimento da qualidade de voar inerente aos objetos; o odor, com a faculdade dos objetos de se dispersarem. As palavras devem existir em liberdade e não presas ao procedimento linear, fixadas pela sintaxe e pelas convenções gramaticais. O tipo e a escrita libertam-se da opressão de serem meros suportes de sentido. (2000, p. 70).

A descrição dos ciberpoemas por Gruszynski e Capparelli distancia essa prática de multiletramento literária da ideologia da gramática tradicional, baseada na concepção de língua padrão e norma culta, aproximando-a da concepção defendida por Kress (2000) de que todo objeto textual deve ser tratado como multimodal. A aproximação com a concepção de multimodalidade desenhada por Kress ocorre não apenas pela compreensão de que os ciberpoemas são realizados através de vários modos semióticos, mas especialmente pelo fato de tal realização ocorrer em relação estreita com as formas como o corpo humano vivencia os significados co-construídos com seus diferentes sentidos: "o som, com a busca do dinamismo dos objetos; o peso, com o reconhecimento da qualidade de voar inerente aos objetos; o odor, com a faculdade dos objetos de se dispersarem".

No compasso das novidades tecnológicas, Gruszynski e Capparelli criaram em 2000, o projeto Ciberpoesia, agregando 12 poesias visuais, que o leitor tem a oportunidade de visitar e deixar um comentário no painel de recados, e mais 10 ciberpoemas, nos quais o internauta é convidado a compor o seu próprio poema ao clicar e arrastar os mais variados elementos disponíveis na tela. Conforme atestam os autores, o projeto foi dividido em três fases. Em sua primeira fase, os autores criaram 28 poemas visuais, mesclando imagens típicas do mundo virtual com pintura de artistas consagrados. Na segunda, oito poemas foram transformados em poemas com superfícies de hipertexto e somente na terceira fase os ciberpoemas se concretizaram, pois foram de fato trabalhados por um estúdio profissional. 
Figura 3 - Ciberpoemas.

\section{Chá}

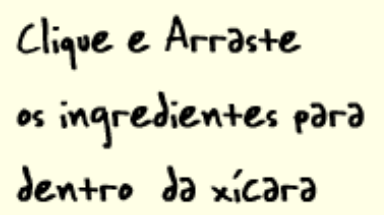

para preparar seu chá.

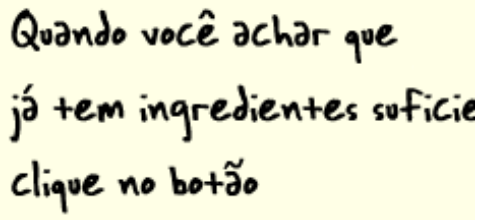

avance

Fonte: www.ciberpoesia.com.br. Acesso em 10/11/2014.

Em uma leitura mais detalhada do poema Chá, observamos que a possibilidade de interação entre leitor e autor é propiciada pela convergência de muitas linguagens. Os autores da Ciberpoesia assim se manifestam, colocando em relevo a hipertextualidade e a interatividade enquanto técnica, o que permite um entrelaçamento com a concepção do Círculo de Bakhtin no que concerne à natureza interativa da linguagem. Voloshinov postula que sendo a linguagem de natureza social e constituída socialmente, a palavra e a comunicação são, portanto, "produtos da interação do locutor e do ouvinte" (VOLOSHINOV, [1929] 1999, p. 13)

O ciberpoema Chá mostra algumas dessas possibilidades [de interatividade], estabelecendo uma zona de diálogo com o leitor que, se quiser apreender o poema, deverá agir e reagir e a cada ação/reação recriar um poema novo. Em outras palavras, a xícara inerte na tela do computador requer comandos por parte do navegador para se mostrar. Só então tem-se surpresas inesperadas, como as sonoridades dos ingredientes para o chá ou do bule de cujo bico vertem letras. (CAPPARELLI; GRUSZYNSKI; KMOHAN, 2000. p. 80.)

Para a leitura do poema Chá, o leitor-internauta terá na tela do seu computador uma xícara vazia, uma colher pequena de chá, um bule, um sachê de chá e as imagens contendo um casal se beijando, estrelas e corações. Todos esses elementos estão à disposição do leitor, para que este os arraste a seu gosto para dentro da xícara, acrescentando a água do bule, a colher e clicando na palavra "Pronto". A colher faz o movimento 
de mexer utilizando a sonoridade, e, conforme os autores assinalam, "então tem-se surpresas inesperadas, como as sonoridades dos ingredientes para o chá ou do bule de cujo bico vertem letras" (2000, p. 80).

Figura 4 - Ciberpoemas.

\section{Chá}

Clique e Arraste

os ingredientes para

dentro da xícara

para preparar seu chá.
Quando você achar que já tem ingredientes soficientes

clique no botz̃o

avance

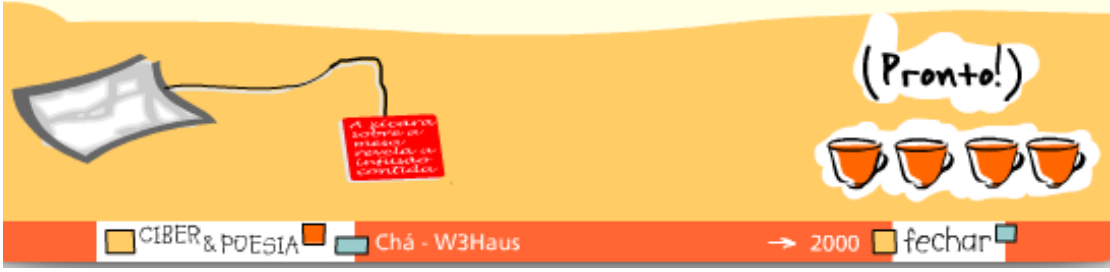

Fonte: www.ciberpoesia.com.br. Acesso em 11/12/2014.

O poema propriamente dito aparece na fumaça que sai da xícara, e a depender dos "ingredientes escolhidos", as letras do poema aparecerão com cores e formatos diferentes. Entretanto, embora seja um poema interativo, a mensagem resultante da elaboração do chá continuará a ser a mesma, enquanto construção, mas ao mesmo tempo, uma outra pelas motivações rítmicas e visuais: "Deixe a infusão / o tempo necessário / até que os nossos aromas / e os nossos sabores / se misturem." Nota-se que a organização da linguagem poética, na mensagem final, revela-se nas metáforas presentes: "até que os nossos aromas e os nossos sabores se misturem" que, além da fruição estética, demandam do leitor-internauta a reflexão sobre como as diferentes semioses mobilizadas no processo de co-construção do ciberpoema colaboram para a construção do sentido metafórico revelado no seu modo de realização escrito. 
A textualidade no poema Chá não se restringe, portanto, ao uso da palavra, tendo em vista que nele concorrem outros modos de realização semiótica como a imagem, o som e o movimento, de forma que a significação não depende da compreensão isolada da palavra, mas do diálogo entre as diferentes linguagens, demonstrando que o destaque do ciberpoema não se situa sobre a mensagem textual, pois, essa é apenas uma dentre as outras linguagens digitais, formando um todo que se complementa. Conforme sinaliza Sergio Capparelli et al (2000, p. 80) "pode se falar que neste ciberpoema, a escrita se dilui na mágica dos movimentos e dos sons e é vista apenas nos vãos das imagens". A sonoridade no ciberpoema Chá se efetiva na interatividade com o leitor, pois ao colocar o mouse sobre a foto dos namorados, por exemplo, o som de um beijo é acionado. As estrelas, quando "ativadas", acionam um som metálico, os corações imitam o som de batimentos cardíacos e o bule ativa o som de louça. Ao término, o leitor será ovacionado pelo seu desempenho com aplausos que o congratulam por ter elaborado um novo poema, tornando-se, em certa medida, coautor do mesmo. No que se refere ao funcionamento e à estrutura, o ciberpoema em tela possui recursos semelhantes ao de jogos eletrônico, tais como a advertência ao jogador quando este se esquece de algum componente (no ciberpoema o aviso é acionado quando falta um elemento essencial para o preparo do chá) e os aplausos finais ao leitor-internauta.

Vale ressaltar que podemos encontrar rastros da interatividade do ciberpoema na obra O Jogo da Amarelinha, de Júlio Cortázar, publicada em 1963. No jogo lúdico da narrativa do escritor argentino, há uma ruptura na linearidade. No poema Chá, por outro lado, embora haja movimento proporcionado pelo recurso digital, a sequência textual permanece dentro da linearidade. Apesar dessa diferença, em ambos os textos o enunciado é o mesmo, apesar das ações do leitor. Nesse sentido, a participação do leitor em ambas as obras é incentivada, mas dirigida, pois ao leitor-internauta não é permitido produzir o seu poema sem inserir o sachê ou a água em Chá, assim como ocorre na narrativa de Cortázar, pois, não se compreende o texto na sua completude caso o trajeto a partir da numeração proposta pelo autor não seja seguido.

Para a produção do ciberpoema, mobiliza-se a presença de outros profissionais, notadamente, os de design na web, o 
que denota que há uma descentramento da autoria centrada no poeta, ou seja, essa junção de profissionais torna a obra coletiva e já estabelece uma interação desde a elaboração do poema digital, colocando em xeque a própria noção de autoria.

Além da versão em ciberpoema, o site de Caparelli et. al traz a opção "Poemas visuais", ou seja, ao internauta/leitor são dadas duas opções: a interativa e a visual, através da qual, é possível ler os poemas na tela, dentro do simulacro de um livro, onde é permitido ao leitor passar a página com um clique ou utilizar o recurso do zoom, adaptando o tamanho das letras conforme preferência. Essas ações, embora pareçam simples, permitem ao interlocutor transitar entre os papéis de leitor e navegador, propiciando uma interação entre texto e leitor que, além de privilegiar a hibridização de múltiplas semioses no processo de construção e (re) interpretação de significados, oferece ao leitor a possibilidade de (re)desenhar suas trajetórias de leitura em caminhos interpretativos bastante distintos daqueles legitimados em práticas tradicionais de ensino de literatura.

\section{Considerações finais}

Nesse momento, perguntamos: Seria o fim do livro no seu suporte de papel? Seria o término das bibliotecas que abrigam os livros de papel? De acordo com Chartier, não teríamos o fim do livro ou da biblioteca de papel, pois ambos possuem um espaço na cultura e na relação necessária que estabelecemos com o passado: "A biblioteca eletrônica sem muros é uma promessa do futuro, mas a biblioteca material, na sua função de preservação das formas sucessivas da cultura escrita, tem, ela também, um futuro necessário." (1999, p.153).

Se, de certa forma, "a biblioteca sem muros" prevista por Chartier no final do milênio já é uma realidade, deveria a escola ignorá-la de forma a se manter como um lócus de preservação da literatura em papel e dos clássicos? Seria a "literatela" uma ameaça para tal preservação? Se, então, a escola acolher a ciberliteratura, quais as possíveis implicações linguístico-pedagógicas?

Em relação às duas primeiras perguntas, compartilhamos com Chartier a ideia de que os diferentes suportes e espaços continuarão a desempenhar seus papéis histórico-culturais 
também na esfera educacional. Nesse sentido, não se trata da "literatela" ameaçar ou substituir totalmente as formas de (multi)letramentos literárias já legitimadas na escola. Trata-se, outrossim (e aí já entramos na terceira pergunta), de expandir os multiletramentos literários para:

- legitimar novas formas de fruição estética;

- estabelecer relações histórico-ideológicas entre gêneros que (re)circulam em diferentes suportes (papel e web, por exemplo);

- analisar como processos de (re)circulação e (re) distribuição de gêneros no meio impresso e eletrônico transformam o próprio gênero, os processos de construção de significados, a interação autor-leitores etc;

- analisar processos de hibridização de gêneros, estilos, semioses na "literatela" e na literatura impressa;

- experimentar a linguagem multimodal e corporificada em que diferentes sentidos e semioses são convocados em processos de (re/des)construção de significados de textos literários;

- compreender como relações de autoria e autoridade literária se estabelece na literatura impressa e na "literatela" e os conflitos que perpassam tais relações;

- acessar inúmeras (re)leituras e se projetar como leitor-navegante em (inter)ações em uma biblioteca em rede composta por links, hiperlinks, imagens, vídeos, áudios etc;

- tornar-se mais do que leitor-navegante de textos literários na Internet, um "lautor" capaz de se apropriar de práticas de multiletramentos literárias para redesenhá-las.

Essas são algumas dentre inúmeras implicações linguístico-pedagógicas que abrir os muros da escola para a ciberliteratura pode trazer para as práticas de (multi) letramentos literárias na esfera educacional. É claro que práticas pedagógicas envolvendo a ciberliteratura e/ou os diálogos entre gêneros literários que circulam na web e na mídia impressa devem ser sempre (re)situadas de acordo com os lautores-navegantes envolvidos, o projeto políticopedagógico da escola, os interesses interdisciplinares e 
aqueles da comunidade em questão. O que nos parece certo, no entanto, é a impossibilidade de a escola se manter de costas viradas para essas práticas de multiletramentos na medida em que tal exclusão só contribui para aumentar (ainda mais) o abismo entre os mundos da escola e da vida.

\section{REFERÊNCIAS}

ARAÚJO, J. C. Oceano de interações na Internet: tsunami digital na escola? Revista Vida \& Educação. Fortaleza: Brasil Tropical. Ano 3, n. 8. 2006, pp.22-26.

BAKHTIN, M. (1920-24). Para uma filosofia do ato responsável. Organização por Augusto Ponzio e Grupo de Estudos dos Gêneros do Discurso - CEGE/UFsCar. Trad. por Valdemir Miotello; Carlos Alberto Faraco. São Carlos: Pedro \& João Editores, 2010.

. (1953). Gêneros do discurso. In BAKHTIN, M. Estética da criação verbal. Trad. Paulo Bezerra. 6 ed. São Paulo: Martins Fontes, 2011, pp. 262-306.

(1975). Questões de literatura e estética: a teoria do romance. São Paulo: Editora UNESP, 1998. Trad. Aurora Fornoni Bernadini; José Pereira Júnior; Augusto Góes Júnior; Helena Spryndis Nazário; Homero Freitas de Andrade. 4 ed. São Paulo, Ed. UNESP, 1998.

BARTHES, R. O prazer do texto. Trad. J. Guinsburg. São Paulo: Perspectiva, 1987.

BRAIT, B. Bakhtin e a natureza constitutivamente dialógica da linguagem. In: BRAIT, B. (Org.) Bakhtin, Dialogismo e Construção do Sentido. São Paulo: Editora da Unicamp, 1997.

BRASIL. Secretaria de Educação Fundamental. Parâmetros curriculares nacionais: terceiro e quarto ciclos do ensino fundamental: lingua portuguesa. Brasília: MEC/SEF, 1998.

BENJAMIN, W. A Obra de Arte na era de sua reprodutibilidade técnica. In: Magia e técnica, arte e política. Obras escolhidas, trad. Sérgio Paulo Rouanet. São Paulo: Brasiliense, 1996. 
BORGES, J. L. A biblioteca de Babel. In: BORGES, Jorge Luis. Ficções. Trad. Davi Arrigucci Jr. São Paulo: Companhia das Letras, 2007.

BRAGA, D. B. A construção de sentidos em hipertextos: questões de autoria e leitura relevantes para a interação crítica com hipertextos. In: Maximina M. Freire, Maria Helena Vieira Abrahão, Ana Maria Ferreira Barcelos. (Org.). Linguística Aplicada e Contemporaneidade. Campinas: Pontes, 2005, p. 247-268.

CALVINO, I. Seis Propostas para o Próximo Milênio: Lições Americanas. Trad. Ivo Cardoso. São Paulo: Companhia das letras, 1990.

CAPPARELLI, S.; GRUSZYNSKI; A. C.; KMOHAN, G. Poesia visual, hipertexto e ciberpoesia. Revista Famecos. Porto Alegre, $\mathrm{n}^{\mathrm{o}} 13$, dezembro 2000. p. 68-82.

CERTEAU, M. de. A invenção do cotidiano: 1 Arte de fazer. Trad. Ephraim Ferreira Alves. Petrópolis, Vozes, 1994.

CHARTIER, R. A aventura do livro: do leitor ao navegador. São Paulo: Editora Unesp, 1999.

COSCARELLI, C. V. Os dons do hipertexto. Littera: Revista de Lingüística e Literatura. Pedro Leopoldo: Faculdades Integradas Pedro Leopoldo, v.4, n.4, jul/dez, 2006. p.7-19.

COSTA, S. R. Dicionário de Gêneros Textuais. Belo Horizonte: Autêntica, 2009.

DANTAS, A.; R. FREIRE, C. RODRIGUES, S. COSTA, S. LOPES. Ciberpoesia: um híbrido infinitamente colaborativo. In: IX Congresso de Ciências da Comunicação na Região Norte. Rio Branco - AC: Universidade Federal do Acre, 27 a 29 de maio 2010, Anais. Disponível em http://www.intercom.org.br/papers/ nacionais/2010/resumos/R5-2684-1.pdf. Acesso em 02/10/2015.

GASTON, S. Derrida. Trad. Vinícius Duarte Figueira. Porto Alegre: Artmed, 2012.

GRUPO DE NOVA LONDRES. A pedagogy of multiliteracies: designing social futures. In: COPE, B.; KALANTZIS, M. (Ed.). Multiliteracies: literacy learning and the design of social futures. Routledge, 2000, p. 9-37. 
KLEIMAN, A. Texto e leitor: aspectos cognitivos da leitura. 7. ed. Campinas, SP: Pontes, 2000.

KOCH, I. G. V. Desvendando os segredos do texto. $4^{\mathrm{a}}$ ed. São Paulo: Cortez, 2005.

KRESS, G. Multimodality. In: COPE, B.; KALANTZIS, M. (Ed.). Multiliteracies: literacy learning and the design of social futures. Routledge, 2000, p. 182-202.

LANDOW, G. Hipertexto. La convergência de la teoría crítica contemporánea y la tecnologia. Barcelona: Ediciones Paidós, 1995. Col. Hipermedia $\mathrm{N}^{\circ} 2$.

LUKE, C. Cyber-schooling and technological change: multiliteracies for new times. In: COPE, B.; KALANTZIS, M. (Ed.). Multiliteracies: literacy learning and the design of social futures. Routledge, 2000, p. 60-91.

MARCUSCHI, L. A. Gêneros textuais emergentes no contexto da tecnologia digital In: MARCUSCHI, L. A.; XAVIER, A. C. (org). Hipertexto e gêneros digitais. 2 ed. Rio de Janeiro: Lucerna, 2005.

OLIVEIRA, L. C. Literatela - quando a literatura é lida na tela. In: Gazeta do Povo, 23/10/2010. http://www.gazetadopovo.com. br/blog/sobretudo/?id=1060461. Acesso em 15/01/2013.

OLIVEIRA, M. B. F.;SZUNDY, P. T.C. Práticas de multiletramentos na escola: por uma educação responsiva à contemporaneidade. Bakhtiniana, São Paulo, 9 (2): 184-205, Ago. / Dez. 2014, pp. 184-205.

ROJO, R. H. R. Letramentos múltiplos: escola e inclusão social. São Paulo: Parábola Editorial, 2008.

ROJO, R. H. R.; MOURA, E. Multiletramentos na Escola. São Paulo: Parábola Editorial, 2012.

ROJO,R. H. R. Escola conectada: os multiletramentos e as TICS. São Paulo: Parábola, 2013a.

R. H. R. Materiais didáticos no ensino de línguas. In: Moita Lopes, L. P. (Org.). Linguística Aplicada na Modernidade Recente - Festschrift para Antonieta Celani. São Paulo, SP: Parábola Editorial, 2013b, p. 163-196. 
SCHNEUWLY, B.; DOLZ, J. et al. Gêneros Orais e Escritos na Escola. Tradução e organização Roxane Rojo e Glaís Sales Cordeiro. São Paulo: Campinas, Mercado de letras, 2004.

SZUNDY, P. T. C. Educação como ato responsável: a formação de professores de linguagens a luz da filosofia da linguagem do Círculo de Bakhtin. Trabalhos em Linguística Aplicada, Campinas, n. 53.1, 2014, p. 13-32.

VERSIANI, Z. A diversidade da produção poética para crianças e jovens. In: PAIVA, A.; EVANGELISTA, A.; PAULINO, G.; VERSIANI, G. (Orgs.) O jogo do livro infantil e juvenil. 2 ed. Belo Horizonte: Autêntica, 2003.

VOLOSHINOV, V. N. (1929). Marxismo e filosofia da linguagem: problemas fundamentais do método sociológica na ciência da linguagem. Trad. Michel Lahud; Yara Frateschi Vieira. 9 ed. São Paulo: Editora Hucitec, 1999.

\section{SITES CONSULTADOS}

http://www.unicamp.br/ hans/mh/intersec.html. Acesso em 10/11/2014.

http://www.capparelli.com.br/ Acesso em 10/11/2014.

http://www.ciberpoesia.com.br/ Acesso em 10/11/2014. 


\section{Abstract}

\section{Surfer-readers of literary texts and hypertexts}

This paper aims at reflecting about reading practices of literary texts resignified in the web so as to create intelligibility about the (multi)literacies of the literary sphere with which contemporary readers engage in the virtual world. In order to comprehend these practices we seek for theoretical framework in constructs about reading and literary readers (CERTEAU, 1994; CHARTIER, 1998; BARTHES, 1987), multiliteracies (COPE, KALANTZIS et al, 2000; ROJO, 2012, 2013) and in the notions of dialogism, speech genre and hybridism designed by the Circle of Bakhtin (VOLOSHINOV, 1929 [1999]; BAKHTIN, 1953 [2011]). In an exercise to (re)think how surfer-readers of texts and hypertexts (re/de) construct meanings about literary texts in the web, we finish the paper with an analysis of multiliteracies practices with cyberpoems in the website ciberpoesia. com.br.

Keywords: surfer-readers, hypertexts, cyberpoems, multiliteracies 